\title{
Ficus deltoidea Jack: A Review on Its Phytochemical and Pharmacological Importance
}

\author{
Hamidun Bunawan, ${ }^{1}$ Noriha Mat Amin, ${ }^{2}$ Siti Noraini Bunawan, \\ Syarul Nataqain Baharum, ${ }^{1}$ and Normah Mohd Noor ${ }^{1}$ \\ ${ }^{1}$ Institute of Systems Biology, Universiti Kebangsaan Malaysia, 43600 Bangi, Selangor, Malaysia \\ ${ }^{2}$ Biotechnology Research Centre, Malaysian Agricultural Research and Development Institute, \\ P.O. Box 12301, 50774 Kuala Lumpur, Malaysia
}

Correspondence should be addressed to Syarul Nataqain Baharum; nataqain@ukm.my

Received 19 December 2013; Accepted 9 February 2014; Published 18 March 2014

Academic Editor: Mohd Roslan Sulaiman

Copyright (C) 2014 Hamidun Bunawan et al. This is an open access article distributed under the Creative Commons Attribution License, which permits unrestricted use, distribution, and reproduction in any medium, provided the original work is properly cited.

Ficus deltoidea Jack (Moraceae) has had a long history of use in traditional medicine among the Malays to alleviate and heal ailments such as sores, wounds, and rheumatism and as an after-birth tonic and an antidiabetic drug. Modern pharmacological studies demonstrated that this plant has a wide variety of beneficial attributes for human health. Despite its importance, a review of this species has not been published in the scientific literature to date. Here, we review and summarize the historic and current literature concerning the botany, traditional uses, phytochemistry, pharmacological effects, and toxicity of this wonder plant. This summary could be beneficial for future research aiming to exploit the therapeutic potential of this useful, medicinal species.

\section{Introduction}

For many years there has been a tremendous interest in biological products gained from megadiversity countries like Malaysia. These invaluable products are explored for the potential discovery of novel biomolecules that have possible future uses. Recently, natural plant products have been gaining popularity in the prevention and treatment of various diseases. Traditional medicines from plants have attracted major attention worldwide because of their potential pharmaceutical importance.

One of the most popular and well-known plants with a long history of use among the Malays is Ficus deltoidea Jack, a plant of the family Moraceae. Ficus deltoidea not only has been used as a medicine for various ailments in the Malay Archipelago, but also has been distributed and formulated as capsules, tea, and tonic tea throughout Malaysia. This review will unify fragmented information regarding $F$. deltoidea in terms of its botany, traditional uses, phytochemistry, and pharmaceutical effects in order to facilitate better understanding and provide further support for the ethnopharmacological use of this important species.

\section{Botany}

2.1. Botanical Name. Its botanical name is Ficus deltoidea Jack.

2.1.1. Subsp. Deltoidea. The synonyms are F. deltoidea var. angustifolia (Miq.) Corner, F. deltoidea forma angustissima Corner, F. deltoidea var. arenaria Corner, F. deltoidea var. bilobata Corner, F. deltoidea var. borneensis Corner, F. deltoidea forma subhirsuta Corner, F. deltoidea var. kunstleri (King) Corner, F. deltoidea var. lutescens (Desf.) Corner, F. deltoidea forma longipedunculata Corner, F. deltoidea forma subsessilis (Miq.) Corner, F. deltoidea var. peltata Corner, 

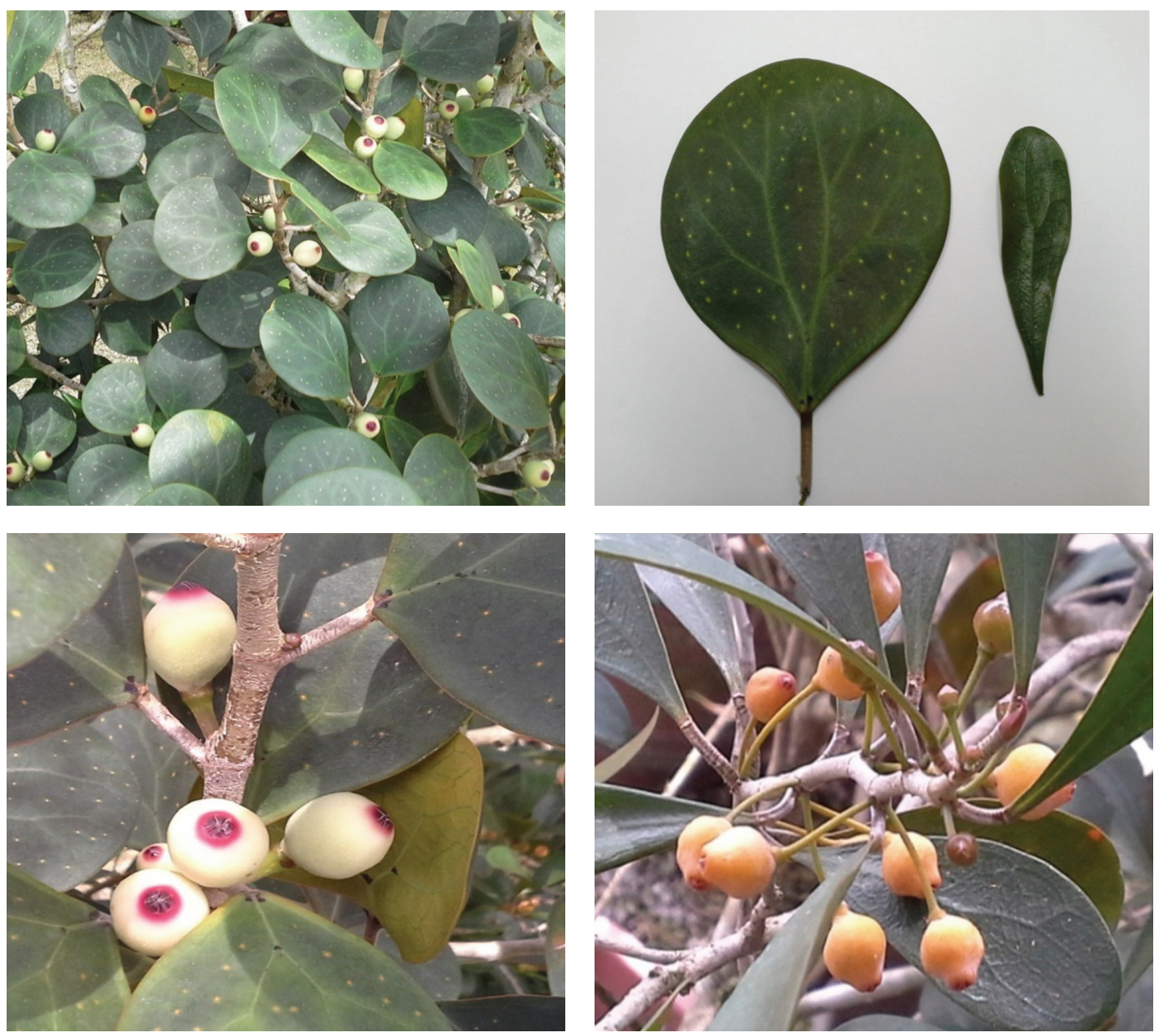

Figure 1: Ficus deltoidea commonly known as Mas Cotek in Malaysia.

F. deltoidea var. recurvata Kochummen, and F. deltoidea var. trengganuensis Corner [1].

2.1.2. Subsp. motleyana (Miq.) C.C Berg, Comb. and Stat. Nov. The synonym is F. deltoidea var. oligoneura (Miq.) Corner [1].

2.2. Common Names. It is commonly known as mistletoe fig and also as Mas Cotek, Telinga Beruk, or Serapat Angin by Malays. Other vernacular names include Sempit-Sempit and Agoluran for people in Sabah, Sarawak, and the Kalimantan Islands, Tabat Barito in Indonesia, and Kangkalibang in Africa.

2.3. Botanical Description and Distribution. Ficus deltoidea is an evergreen shrub that reaches a height of 2 meters, with whitish grey bark, leaves broadly spoon-shaped to obovate, with a leaf length between $4 \mathrm{~cm}$ and $8 \mathrm{~cm}$, coloured bright green above, and rust-red to olive-brown beneath. The plant produces figs that are spherical to round, with a width of 1.0 to $1.5 \mathrm{~cm}$ and coloured yellow to orange-red (Figure 1). This plant is native to the Malayan Archipelago and has been introduced elsewhere. It is distributed throughout the region known as Malesia, which includes Thailand, Indonesia, and Malaysia [2].

\section{Ethnobotanical Uses}

Malays in the Peninsular Malaysia have been using the powdered root and leaves of $F$. deltoidea to treat wounds, rheumatism, sores, and other ailments for centuries. The decoction of boiled leaves of F. deltoidea is traditionally used as an antidiabetic treatment and an after-birth tonic to contract the uterus and vaginal muscles, to treat disorders of the menstrual cycle, and also to treat leucorrhoea [3]. Additionally, $F$. deltoidea fruits are traditionally chewed to relieve toothache, cold, and headache and the entire Ficus deltoidea plant is also traditionally used as an aphrodisiac tonic and as health tonic by women in Indonesia.

\section{Chemical Composition}

A wide range of chemical compounds have been isolated and characterized from $F$. deltoidea, particularly from the leaves and figs. An initial comprehensive study on volatile compounds produced by the fruits was conducted by GrisonPigé et al. [4, 5]. The volatile compounds isolated and identified are mainly products of the shikimic acid pathway, terpenoids, and aliphatic groups, generally present as floral fragrances in plants. In 2009, Mohd Lip et al. [6] isolated and identified moretenol from $F$. deltoidea leaves using nuclear magnetic resonance (NMR) and mass spectrometers. Later on, an antibacterial compound known as lupeol $\left(\mathrm{C}_{30} \mathrm{H}_{50} \mathrm{O}\right)$ 


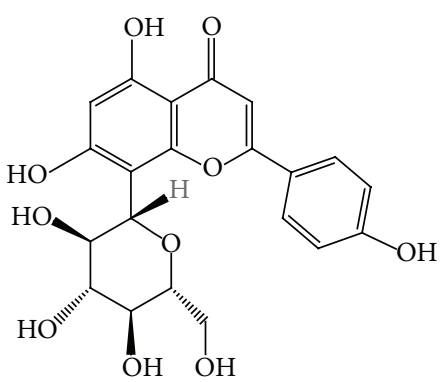

(a)<smiles></smiles>

(b)

FIgURE 2: (a) Vitexin and (b) isovitexin chemical structures.

was also isolated from the leaves of F. deltoidea and exhibited toxicity against Staphylococcus aureus, Bacillus subtilis, and Escherichia coli [7]. Ong et al. [8] demonstrated enhancement of flavonoid compounds (rutin, quercetin, and naringenin) in cell cultures of $F$. deltoidea influenced by different carbon sources as well as plant growth regulators. A comprehensive study on flavonoid compounds of aqueous extract of $F$. deltoidea was conducted by Omar et al. [9] using HPLCMS-based methodology and more than 25 compounds were identified. Currently, two bioactive constituents known as vitexin and isovitexin have been isolated, identified, and evaluated to show $\alpha$-glucosidase inhibition [10]. The metabolites identified from F. deltoidea to date are presented in Table 1.

\section{Pharmacological Properties}

5.1. Antidiabetic. Ficus deltoidea is traditionally used in Malaysia to control blood sugar levels. Adam et al. [11] evaluated the potential of five extracts and three fractions of F. deltoidea in order to enhance basal and insulin-stimulated glucose uptake into the Chang liver cell line. The results show that $F$. deltoidea extracts and fractions, with the exception of petroleum ether, possess the potential to stimulate basal and insulin-stimulated glucose uptake into the liver cell line, with ethanolic extract having the highest insulin mimetic activity. Another study by Adam et al. [12] reported that hot aqueous, ethanolic, and methanolic extracts of $F$. deltoidea inhibit rat intestine $\alpha$-glucosidase activity significantly, an enzyme that is accountable for carbohydrate digestion to condense the effect of carbohydrate in blood sugar. This was supported in an animal model in which all extracts reduced postprandial hyperglycemia after sucrose administration. Methanolic extract was found to be the most potent inhibitor of $\alpha$-glucosidase [12].

Another study by Farsi et al. [13] reported that the nbutanol fraction from the leaves of $F$. deltoidea showed visible $\alpha$-glucosidase and $\alpha$-amylase inhibitory effects to control postprandial hyperglycemia. A different study conducted by Adam et al. [14] to evaluate the ethanolic effect of $F$. deltoidea on glucose levels in normal rats showed that all doses reduced fasting blood glucose, especially after 6 hours of administration. Adam et al. [15] also evaluated extracts of $F$. deltoidea for hyperglycemia effects at different prandial states. The study found that hot aqueous extracts of F. deltoidea stimulate insulin secretion and show a high magnitude of stimulation and the extract induced the usage of intracellular $\mathrm{Ca}^{2+}$ to initiate release of insulin, whilst increased basal and insulin-mediated glucose uptake into adipocytes cells was observed with ethanolic and methanolic extracts.

Partitioned extracts, subfractions, and pure bioactive constituents were the subject of an $\alpha$-glucosidase inhibition assay. Both vitexin and isovitexin significantly reduced postprandial blood glucose level in mice, were nontoxic even at the highest dose of $2 \mathrm{~g}$ per $\mathrm{kg}$, and exhibited in vivo $\alpha$-glucosidase activity (Figure 2) [10]. Draman et al. [16] evaluated the effects of $F$. deltoidea leaves on fasting blood sugar and renal and lipid profiles of type 2 diabetic humans in Malaysia. The patients were given $F$. deltoidea $350 \mathrm{mg}$ orally twice daily for two months. Even though the patients reported feeling energetic and fresh, effects on fasting blood sugar, HbA1C, and renal and lipid profiles were not significant. On the other hand, Kalman et al. [17] reported that $F$. deltoidea has significant effect on reducing glucose and lipid levels in human body after testing the antidiabetic effects of $F$. deltoidea in adults with prediabetes.

Recently, the fruits of two varieties of F. deltoidea, var. angustifolia and var. kunstleri, were separately extracted and the antidiabetic activities were evaluated according to the ability of the extract to inhibit both yeast and mammalian $\alpha$ glucosidase and $\alpha$-amylase [18]. The study also found that the crude extracts and fractions of both varieties hindered yeast and rat intestinal $\alpha$-glucosidases depending on dose used but failed to inhibit porcine pancreatic $\alpha$-amylase.

5.2. Anti-Inflammatory and Antinociceptive Activity. The anti-inflammatory activity of the aqueous extract of $F$. deltoidea leaf has been evaluated in rats using a carrageenaninduced paw edema test, a cotton pellet-induced granuloma test, and a formalin test, demonstrating that F. deltoidea 
TABLE 1: Chemical constituents identified in F. deltoidea.

\begin{tabular}{|c|c|c|c|}
\hline Plant part used & Compound & Class & References \\
\hline \multirow{48}{*}{ Fig } & 4-Methylbenzaldehyde & Shikimic acid & {$[4]$} \\
\hline & Methyl benzoate & Shikimic acid & {$[4]$} \\
\hline & Indole & Shikimic acid & {$[4]$} \\
\hline & Decanal & Aliphatics & {$[4]$} \\
\hline & 6-Methyl-5-hepten-2-one & Acyclic monoterpenes & {$[4]$} \\
\hline & Myrcene & Acyclic monoterpenes & {$[4]$} \\
\hline & (Z)- $\beta$-Ocimene & Acyclic monoterpenes & {$[4]$} \\
\hline & (E)- $\beta$-Ocimene & Acyclic monoterpenes & {$[4]$} \\
\hline & cis-Furanoid linalool oxide & Acyclic monoterpenes & {$[4]$} \\
\hline & trans-Furanoid linalool oxide & Acyclic monoterpenes & {$[4,5]$} \\
\hline & Linalool & Acyclic monoterpenes & {$[4,5]$} \\
\hline & cis-Pyranoid linalool oxide & Acyclic monoterpenes & {$[4]$} \\
\hline & trans-Pyranoid linalool oxide & Acyclic monoterpenes & {$[4]$} \\
\hline & Hotrienol & Acyclic monoterpenes & {$[4]$} \\
\hline & Perillene & Acyclic monoterpenes & {$[4]$} \\
\hline & Limonene & Cyclic monoterpenes & {$[4]$} \\
\hline & Dendrolasine & Sesquiterpenes & {$[4]$} \\
\hline & $\alpha$-Cubebene & Sesquiterpenes & {$[4]$} \\
\hline & Cyclosativene & Sesquiterpenes & {$[4]$} \\
\hline & A-Ylangene & Sesquiterpenes & {$[4]$} \\
\hline & $\alpha$-Copaene & Sesquiterpenes & {$[4,5]$} \\
\hline & $\beta$-Bourbonene & Sesquiterpenes & {$[4]$} \\
\hline & 1,5-Diepi- $\beta$-bourbonene & Sesquiterpenes & {$[4]$} \\
\hline & $\beta$-Cubebene & Sesquiterpenes & {$[4,5]$} \\
\hline & $\beta$-Elemene & Sesquiterpenes & {$[4]$} \\
\hline & $\alpha$-Gurjunene & Sesquiterpenes & {$[4]$} \\
\hline & $\alpha$-cis-Bergamotene & Sesquiterpenes & {$[4]$} \\
\hline & $\beta$-Caryophyllene & Sesquiterpenes & {$[4,5]$} \\
\hline & $\alpha$-Santalene & Sesquiterpenes & {$[4]$} \\
\hline & Selina-3-6-diene & Sesquiterpenes & {$[4]$} \\
\hline & $\alpha$-trans-Bergamotene & Sesquiterpenes & {$[4,5]$} \\
\hline & $\alpha$-Humulene & Sesquiterpenes & {$[4,5]$} \\
\hline & Alloaromadendrene & Sesquiterpenes & {$[4,5]$} \\
\hline & Aciphyllene & Sesquiterpenes & {$[4]$} \\
\hline & Germacrene D & Sesquiterpenes & {$[4,5]$} \\
\hline & $\beta$-Selinene & Sesquiterpenes & {$[4]$} \\
\hline & $\alpha \mathrm{d}$-Selinene & Sesquiterpenes & {$[4]$} \\
\hline & $\alpha$-Selinene & Sesquiterpenes & {$[4]$} \\
\hline & Bicyclogermacrene & Sesquiterpenes & {$[4]$} \\
\hline & $\alpha$-Muurolene & Sesquiterpenes & {$[4]$} \\
\hline & Germacrene A & Sesquiterpenes & {$[4,5]$} \\
\hline & $\delta$-Amorphene & Sesquiterpenes & {$[4]$} \\
\hline & (E,E) $\alpha$-Farnesene & Sesquiterpenes & {$[4,5]$} \\
\hline & 2-epi- $\alpha$-Selinene & Sesquiterpenes & {$[4]$} \\
\hline & $\delta$-Cadinene & Sesquiterpenes & {$[4,5]$} \\
\hline & Cadina-1,4-diene & Sesquiterpenes & {$[4]$} \\
\hline & Germacrene B & Sesquiterpenes & {$[4]$} \\
\hline & Caryophyllene oxide & Sesquiterpenes & {$[4]$} \\
\hline
\end{tabular}


TABle 1: Continued.

\begin{tabular}{|c|c|c|c|}
\hline Plant part used & Compound & Class & References \\
\hline \multirow{22}{*}{ Leaves } & Gallocatechin & Flavonoids & [9] \\
\hline & Epigallocatechin & Flavonoids & {$[9]$} \\
\hline & Catechin & Flavonoids & {$[9]$} \\
\hline & (Epi)afzelechin-(epi)catechin & Flavonoids & {$[9]$} \\
\hline & (Epi)afzelechin-(epi)afzelechin & Flavonoids & {$[9]$} \\
\hline & (Epi)catechin Epicatechin & Flavonoids & {$[9]$} \\
\hline & Luteolin-6,8-C-diglucoside (lucenin-2) & Flavonoids & {$[9]$} \\
\hline & Apigenin-6,8-C-diglucoside (vicenin-2) & Flavonoids & {$[9]$} \\
\hline & Luteolin-6-C-hexosyl-8-C-pentoside & Flavonoids & {$[9]$} \\
\hline & Luteolin-6-C-glucosyl-8-C-arabinoside & Flavonoids & {$[9]$} \\
\hline & Apigenin-6-C-arabinosyl-8-C-glucoside (isoschaftoside) & Flavonoids & {$[9]$} \\
\hline & Luteolin-6-C-arabinosyl-8-C-glucoside & Flavonoids & {$[9]$} \\
\hline & Apigenin-6-C-glucoside-8-C-arabinoside (schaftoside) & Flavonoids & {$[9]$} \\
\hline & Luteolin-8-C-glucoside (orientin) & Flavonoids & {$[9]$} \\
\hline & Apigenin-6-C-pentosyl-8-C-glucoside & Flavonoids & {$[9]$} \\
\hline & Apigenin-8-C-glucoside (vitexin) & Flavonoids & {$[9,10]$} \\
\hline & Apigenin-6-C-glucosyl-8-C-pentoside & Flavonoids & [9] \\
\hline & Apigenin-6,8-C-dipentoside isomer & Flavonoids & {$[9]$} \\
\hline & Apigenin-6-C-glucoside (isovitexin) & Flavonoids & {$[9,10]$} \\
\hline & 4-p-coumarolyquinic acid & Flavonoids & [9] \\
\hline & Moretenol & Terpenes & {$[6]$} \\
\hline & $(3 \beta, 13 \xi)$-Lup-20(29)-en-3-ol (lupeol) & Triterpenes & {$[7]$} \\
\hline \multirow{3}{*}{ Cell culture } & Rutin & Flavonoids & {$[8]$} \\
\hline & Quercetin & Flavonoids & {$[8]$} \\
\hline & Naringenin & Flavonoids & {$[8]$} \\
\hline
\end{tabular}

had significant anti-inflammatory activity in every test with dose-response effects observed [19]. The leaves possess antiinflammatory effects against various inflammatory responses as well as pain-associated inflammatory responses. Previously, Abdullah et al. [20] evaluated standardised extracts of different varieties of $F$. deltoidea for anti-inflammatory activity using three in vitro assays: lipoxygenase, hyaluronidase, and TPA-induced edema. The results demonstrated that extracts of leaves of $F$. deltoidea have significant antiinflammatory properties, suggesting that the extracts may be useful for relieving pain by reducing inflammation.

Antinociceptive activity of $F$. deltoidea aqueous extract from leaves was studied by Sulaiman et al. [21] in order to verify using this plant to reduce sensitivity to painful stimuli using chemical and thermal nociception models. Three methods were used in their experiment: acetic acidinduced abdominal writhing, formalin, and a hot plate test. Significant antinociceptive effects of $F$. deltoidea leaves were observed in all three methods used when administered 30 minutes prior to pain induction. The results demonstrate that F. deltoidea leaves do have antinociceptive activity, corroborating its traditional use in treating painful conditions, such as headache and toothache.
5.3. Antimelanogenic and Antiphotoaging Effect. Ficus deltoidea was also reported to have antimelanogenic effects in reducing melanogenesis biosynthesis for melanin production [22]. Ficus deltoidea extract activity was investigated using cultured B16F1 melanoma cells focusing on the characterization of tyrosinase, the enzyme that is required for melanin production. The extract from $F$. deltoidea inhibited mushroom tyrosinase activity and intracellular tyrosinase activity of B16F1. Microphthalmia-associated transcription factor (MITF) expression also decreased when F. deltoidea extract was applied, suggesting that F. deltoidea has strong potential for use as a depigmenting agent in cosmetics.

Treatment with $F$. deltoidea extract also significantly inhibited UV-induced TNF- $\alpha$, IL- $1 \alpha$, IL-6, and COX-2 expression [23]. Decreased collagen synthesis of fibroblasts as a result of UVB exposure returned to normal after F. deltoidea extract treatment. Furthermore, following UVB irradiation enhanced MMP-1 expression that would usually be observed decreased after treatment with the $F$. deltoidea extract in a dose-dependent manner. The study concluded that the $F$. deltoidea extract may have a positive effect against UVBinduced skin damage and that it is useful for antiphotoaging cosmetic products [23]. 
<smiles>OC1Cc2ccccc2OC1c1ccccc1</smiles>

(a)<smiles>COc1c(O)cc(C2Oc3c(c(O)cc(O)c3[C@@]3(C)c4c(O)cc(O)cc4O[C@H](c4ccc(O)cc4)[C@H]3O)C[C@H]2O)cc1O</smiles>

(b)

Figure 3: Chemical structure of (a) flavan-3-ol monomer and (b) proanthocyanidins.

5.4. Antioxidant Effect. The antioxidant property of the F. deltoidea extract was revealed through a total phenolic content and ferric reducing antioxidant potential (FRAP) assay by Omar et al. [9]. It was found that flavan-3-ol monomers and proanthocyanidins contributed $85 \%$ of the antioxidant activity of the aqueous extract of $F$. deltoidea (Figure 3 ). In contrast, this figure was $15 \%$ for flavones, primarily due to apigenin-6,8-C-diglucoside. Previously, Hakiman and Maziah [24] described another experiment where different aqueous extracts of $F$. deltoidea accessions were evaluated for their antioxidant activities using several assays such as FRAP, free radical scavenging assay, total polyphenol, flavonoid, phenolic acid, and vitamin C.

5.5. Antiulcerogenic Effect. The potential of F. deltoidea whole-plant extract as an ulcer healing agent for gastric ulcers caused by ethanol in Sprague Dawley rats was investigated by Zahra et al. [25]. Four groups of rats were used in the experiment: negative controls (treated with distilled water), 250 and $500 \mathrm{mg} \mathrm{kg}^{-1}$ of F. deltoidea extract, and positive controls (treated with omeprazole). Pretreatment with $F$. deltoidea extract demonstrated considerably less gastric mucosal lesions produced by ulcerogens compared to the negative control. Predictably, gastric protection was more effective with use of $500 \mathrm{mg} \mathrm{kg}^{-1} \mathrm{~F}$. deltoidea extract compared to $250 \mathrm{mg} \mathrm{kg}^{-1}$. The negative control rats showed very severe gastric mucosal damage as well as edema and leucocyte permeation of the submucosal layer, suggesting that F. deltoidea extract protects against ulcers, demonstrated by the reduction in ulcer areas, inhibition of submucosal edema, and reduced leucocyte infiltration.

5.6. Wound Healing Activity. The effects of F. deltoidea extract for healing of wounds in Sprague Dawley rats were evaluated by Abdulla et al. [26]. The group that was treated with a placebo containing $5 \%$ and $10 \%$ of $F$. deltoidea extracts showed significantly accelerated wound healing in comparison with deionized water (negative control) and blank placebo treatments. The rats treated with F. deltoidea also showed decreased scar width, more fibroblast proliferation, and more collagen fibres accompanied by angiogenesis in the granulation tissue.

5.7. Antibacterial Activity. A study by Uyub et al. [27] found that $F$. deltoidea leaf extract has antimicrobial activity towards Helicobacter pylori, the major agent in chronic gastritis and gastric ulcers. Methanol extracts of F. deltoidea showed highest activity against $H$. pylori with an inhibition zone diameter of $12.0 \pm 0.6 \mathrm{~mm}$ followed by petroleum ether $10.0 \pm$ $0.6 \mathrm{~mm}$ and chloroform extract $8.0 \pm 0.1 \mathrm{~mm}$. Another study found that ethanol and methanol extracts of $F$. deltoidea leaves inhibited growth of Bacillus subtilis [28]. This was further supported by Samah et al. [29] who found methanol extracts of whole $F$. deltoidea exhibited antibacterial activity against Staphylococcus aureus, Bacillus subtilis, Escherichia coli, and Pseudomonas aeruginosa and antifungal activity towards Candida albicans.

5.8. Anticancer Effect. Aqueous and ethanol extracts of F. deltoidea were found to have anticancer activity against human ovarian carcinoma cell line A2780 using a cell-based assay and confirmed by microscopic observation [30]. The plant extracts gave $\mathrm{IC}_{50}$ value of $224.39 \pm 6.24 \mu \mathrm{g} / \mathrm{mL}$ and $143.03 \pm$ $20.21 \mu \mathrm{g} / \mathrm{mL}$ in aqueous and ethanolic extracts, respectively. Both of the plant extracts have different effects on cell growth: the aqueous extract promoted cell detachment, while the ethanolic extract decreased cell proliferation. This might be due to different types of phytochemical property in those two extracts. The study also reported that apoptosis was caused by both extracts at $1000 \mu \mathrm{g} / \mathrm{mL}$.

5.9. Miscellaneous Activity. A study was conducted to assess whether the aqueous and ethanolic extracts of $F$. deltoidea leaves possessed antithrombotic activity and to observe the effect of the extracts on sperm quality and testosterone levels in diabetic rats [31]. These rats were administered alloxan monohydrate, which is known to cause an increase in blood glucose level, blood clotting rate, and sperm abnormalities and a decrease in testosterone level. Interestingly, rats given aqueous and ethanolic leaf extracts of F. deltoidea demonstrated significantly increased testosterone levels, sperm count, and motility and showed a reduction in the blood clotting levels and blood glucose level, as well as a reduction in sperm abnormalities.

Samsulrizal et al. [32] conducted another similar study with the same result and they additionally considered lactate dehydrogenase $\mathrm{C} 4$ (LDH-C4), a specific isoenzyme in mammalian testes that plays a role in sperm capacitation. The effect of F. deltoidea on LDH-C4 activity was also seen positive for maintaining healthy sperm. A further study on the effects of F. deltoidea methanolic extract on the reproductive systems of male rats was conducted by Norrizah et al. [33]. Surprisingly, the study found that the leaf extract decreased testes and 
epididymis weight, sperm count, and sperm viability. Rats treated with stem extract showed a significant increase in epididymis weight and sperm count and viability, although reduction in testes weight and the number of normal sperm morphology was observed.

\section{Cytotoxicity Activity}

Comprehensive attempts have been made on efficiency and safety studies on F. deltoidea [34-36]. A study by Shafaei et al. [35] confirmed that $F$. deltoidea leaves do not contain toxic elements by evaluating toxicological elements (lead, cadmium, arsenic, and mercury) using atomic absorption spectroscopy technique, standardisation parameters (moisture, volatile, total ash, and acid insoluble ash), and Microbial Limit Test (MLT) for microbial contamination.

A genotoxicity study was performed using the Ames test with the TA98 and TA100 Salmonella typhimurium strains and showed the F. deltoidea extract did not have any potential to induce mutations in the presence or absence of S9 metabolic activation [36]. Further study on the acute toxicity showed that the $\mathrm{LD}_{50}$ of the extract was greater than $5000 \mathrm{mg} / \mathrm{kg}$ on Sprague Dawley rats treated with five different doses of the extract. In the subchronic study, there were no significant adverse effects on body weight, organ weight, food consumption, mortality, haematology, histopathology, and clinical chemistry, except an increase in the serum urea level [36].

\section{Conclusions}

The scientific research on F. deltoidea indicated that this plant has received increasing interest in recent years. Ficus deltoidea has been reported to have beneficial pharmaceutical uses as an antidiabetic, anti-inflammatory, antinociceptive, antimelanogenic, antiphotoaging, antioxidant, antiulcerogenic, and antibacterial agent. Phytochemical and pharmaceutical studies have validated the traditional uses of $F$. deltoidea; however, there is a need to investigate the chemical or bioactive components that are responsible for providing the specific properties. The principle bioactive metabolites have to be examined for their bioactivities and their mechanism of action needs to be determined, in conjunction with analysing the pharmacokinetics and physiological pathways of specific compounds in F. deltoidea. These may help to strengthen our understanding of this highly therapeutic plant for commercial exploitation.

\section{Conflict of Interests}

The authors declare no conflict of interests.

\section{Acknowledgments}

This review was funded by UKM Research University Grant (Project no. DLP-2013-024). The authors expressed their thanks to Kathryn Ford and Lukas Dusik for their editorial comments on the paper.

\section{References}

[1] C. C. Berg, "Flora Malesiana precursor for the treatment of Moraceae 3: Ficus subgenus Ficus," Blumea, vol. 48, no. 3, pp. 529-550, 2003.

[2] E. J. H. Corner, "The complex of Ficus deltoidea; a recent Invasion of the Sunda Shelf," Philosophical Transactions of the Royal Society B, vol. 256, pp. 281-317, 1969.

[3] I. H. Burkill and M. Haniff, "Malay village medicine," Garden's Bulletin, vol. 6, no. 2, pp. 167-332, 1930.

[4] L. Grison-Pigé, M. Hossaert-McKey, J. M. Greeff, and J. M. Bessière, "Fig volatile compounds-a first comparative study," Phytochemistry, vol. 61, no. 1, pp. 61-71, 2002.

[5] L. Grison-Pigé, J. M. Bessière, and M. Hossaert-McKey, "Specific attraction of fig-pollinating wasps: role of volatile compounds released by tropical figs," Journal of Chemical Ecology, vol. 28, no. 2, pp. 283-295, 2002.

[6] J. Mohd Lip, D. Nazrul Hisham, J. Arif Zaidi et al., "Isolation and identification of moretenol from Ficus deltoidea leaves," Journal of Tropical Agriculture and Food Science, vol. 37, no. 2, pp. 195201, 2009.

[7] S. Suryati, H. Nurdin, D. Dachriyanus, and M. Hj Lajis, "Structure elucidation of antibacterial compound from Ficus deltoidea Jack leaves," Indonesian Journal of Chemistry, vol. 11, no. 1, pp. 67-70, 2011.

[8] S. L. Ong, A. P. K. Ling, R. Poospooragi, and S. Moosa, "Production of Flavonoid compounds in cell cultures of Ficus deltoidea as influenced by medium composition," International Journal of Medicinal and Aromatic Plants, vol. 1, no. 2, pp. 62-74, 2011.

[9] M. H. Omar, W. Mullen, and A. Crozier, "Identification of proanthocyanidin dimers and trimers, flavone C-glycosides, and antioxidants in Ficus deltoidea, a malaysian herbal tea," Journal of Agricultural and Food Chemistry, vol. 59, no. 4, pp. 1363-1369, 2011.

[10] C. Y. Choo, N. Y. Sulong, F. Man, and T. W. Wong, "Vitexin and isovitexin from the leaves of Ficus deltoidea with in-vivo aglucosidase inhibition," Journal of Ethnopharmacology, vol. 142, no. 3, pp. 776-781, 2012.

[11] Z. Adam, M. Hamid, A. Ismail, and S. Khamis, "Effect of Ficus deltoidea extracts on hepatic basal and insulin-stimulated glucose uptake," Journal of Biological Sciences, vol. 9, no. 8, pp. 796-803, 2009.

[12] Z. Adam, S. Khamis, A. Ismail, and M. Hamid, "Inhibitory properties of Ficus deltoidea on $\alpha$-glucosidase activity," Research Journal of Medicinal Plant, vol. 4, no. 2, pp. 61-75, 2010.

[13] E. Farsi, A. Shafaei, S. Y. Hor et al., "Correlation between enzymes inhibitory effects and antioxidant activities of standardized fractions of methanolic extract obtained from Ficus deltoidea leaves," African Journal of Biotechnology, vol. 10, no. 67, pp. 15184-15194, 2011.

[14] Z. Adam, A. Ismail, S. Khamis, M. H. Mohd. Mokhtar, and M. Hamid, "Antihyperglycemic activity of F. deltoidea ethanolic extract in normal rats," Sains Malaysiana, vol. 40, no. 5, pp. 489495, 2011.

[15] Z. Adam, S. Khamis, A. Ismail, and M. Hamid, "Ficus deltoidea: a potential alternative medicine for diabetes mellitus," EvidenceBased Complementary and Alternative Medicine, vol. 2012, Article ID 632763, 12 pages, 2012.

[16] S. Draman, M. A. M. Aris, A. Razman et al., "Mas cotek (Ficus deltoidea): a possible supplement for type II diabetes: (a pilot 
study)," Pertanika Journal of Tropical Agricultural Science, vol. 35, no. 1, pp. 93-102, 2012.

[17] D. S. Kalman, H. I. Schwartz, S. Feldman, and D. R. Krieger, "Efficacy and safety of Elaeis guineensis and Ficus deltoidea leaf extracts in adults with pre-diabetes," Nutrition Journal, vol. 12, no. 1, article 36, 2013.

[18] H. Misbah, A. A. Aziz, and N. Aminudin, "Antidiabetic and antioxidant properties of Ficus deltoidea fruit extracts and fractions," BMC Complementary and Alternative Medicine, vol. 13, article 118, 2013.

[19] Z. A. Zakaria, M. K. Hussain, A. S. Mohamad, F. C. Abdullah, and M. R. Sulaiman, "Anti-inflammatory activity of the aqueous extract of Ficus deltoidea," Biological Research for Nursing, vol. 14, no. 1, pp. 90-97, 2012.

[20] Z. Abdullah, K. Hussain, I. Zhari, and M. A. Rasadah, "Antiinflammatory activity of standardised extracts of leaves of three varieties of Ficus deltoidea," International Journal of Pharmaceutical and Clinical Research, vol. 1, pp. 100-105, 2009.

[21] M. R. Sulaiman, M. K. Hussain, Z. A. Zakaria et al., "Evaluation of the antinociceptive activity of Ficus deltoidea aqueous extract," Fitoterapia, vol. 79, no. 7-8, pp. 557-561, 2008.

[22] M. J. Oh, M. Abdul Hamid, S. Ngadiran, Y. K. Seo, M. R. Sarmidi, and C. S. Park, "Ficus deltoidea (Mas cotek) extract exerted anti-melanogenic activity by preventing tyrosinase activity in vitro and by suppressing tyrosinase gene expression in B16F1 melanoma cells," Archives of Dermatological Research, vol. 303, no. 3, pp. 161-170, 2011.

[23] R. Hasham, H. K. Choi, M. R. Sarmidi, and C. S. Park, "Protective effects of a Ficus deltoidea (Mas cotek) extract against UVB-induced photoageing in skin cells," Biotechnology and Bioprocess Engineering, vol. 18, no. 1, pp. 185-193, 2013.

[24] M. Hakiman and M. Maziah, "Non enzymatic and enzymatic antioxidant activities in aqueous extract of different Ficus deltoidea accessions," Journal of Medicinal Plant Research, vol. 3, no. 3, pp. 120-131, 2009.

[25] M. A. S. F. Zahra, A. A. Mahmood, M. A. Hapipah, M. N. Suzita, and I. Salmah, "Anti-ulcerogenic activity of aqueous extract of Ficus deltoidea against ethanol-induced gastric mucosal injury in rats," Research Journal of Medical Sciences, vol. 3, no. 2, pp. 42-46, 2009.

[26] M. A. Abdulla, K. Abdul-Aziz Ahmed, F. M. Abu-Luhoom, and M. Muhanid, "Role of Ficus deltoidea extract in the enhancement of wound healing in experimental rats," Biomedical Research, vol. 21, no. 3, pp. 241-245, 2010.

[27] A. M. Uyub, I. N. Nwachukwu, A. A. Azlan, and S. S. Fariza, "Invitro antibacterial activity and cytotoxicity of selected medicinal plant extracts from penang island Malaysia on metronidazoleresistanthelicobacter pylori and some pathogenic bacteria," Ethnobotany Research and Applications, vol. 8, pp. 95-106, 2010.

[28] P. Jamal, I. A. Karim, E. Abdullah, R. A. Raus, and Y. Z. Hashim, "Phytochemical screening for antibacterial activity of potential Malaysian medicinal plants," African Journal of Biotechnology, vol. 10, no. 81, pp. 18795-18799, 2011.

[29] O. A. Samah, N. T. A. Zaidi, and A. B. Sule, "Antimicrobial activity of Ficus deltoidea Jack (Mas Cotek)," Pakistan Journal of Pharmaceutical Sciences, vol. 25, no. 3, pp. 675-678, 2012.

[30] N. A. M. Akhir, L. S. Chua, F. A. A. Majid, and M. R. Sarmidi, "Cytotoxicity of aqueous and ethanolic extracts of Ficus deltoidea on human ovarian carcinoma cell line," British Journal of Medicine and Medical Research, vol. 1, no. 4, pp. 397409, 2011.
[31] S. Nurdiana, A. Z. Mohd Idzham, A. Zanariah, and M. N. Mohd Luqman Hakim, "Effect of Ficus deltoidea leaves extracts on blood clotting, sperm quality and testosterone level in alloxan-induced male diabetic rats," International Journal of Pharmaceutical Sciences Review and Research, vol. 13, no. 1, pp. 111-114, 2012.

[32] N. Samsulrizal, Z. Awang, M. L. H. MohdNajib, M. Idzham, and A. Zarin, "Effect of Ficus deltoidea leaves extracts on sperm quality, LDH-C4 activity and testosterone level in alloxaninduced male diabetic rats," in Proceedings of the 2011 IEEE Colloquium on Humanities, Science and Engineering (CHUSER '11), pp. 888-891, Penang, Malaysia, December 2011.

[33] J. S. Norrizah, A. Norizan, S. A. Sharipah Ruzaina, D. Dzulsuhaimi, and M. S. Nurul Hidayah, "Cytotoxicity activity and reproductive profiles of male rats treated with methanolic extracts of Ficus deltoidea," Research Journal of Medicinal Plant, vol. 6, no. 2, pp. 197-202, 2012.

[34] M. S. Fazliana, In vivo and in vitro toxicity studies of aqueous extract of Mas Cotek (Ficus deltoidea) [M.S. thesis], Universiti Putra Malaysia, Selangor, Malaysia, 2010.

[35] A. Shafaei, E. Farsi, B. M. Khadeer Ahamed et al., "Evaluation of toxicological and standardization parameters and phytochemical investigation of Ficus deltoidea leaves," American Journal of Biochemistry and Molecular Biology, vol. 1, no. 3, pp. 237-243, 2011.

[36] E. Farsi, A. Shafaei, S. Y. Hor et al., "Genotoxicity and acute and subchronic toxicity studies of a standardized methanolic extract of Ficus deltoidea leaves," Clinics, vol. 68, no. 6, pp. 865-875, 2013. 


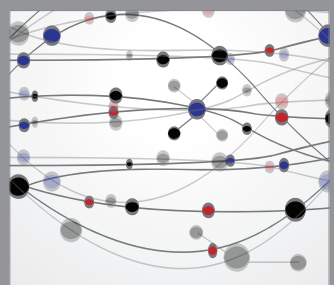

The Scientific World Journal
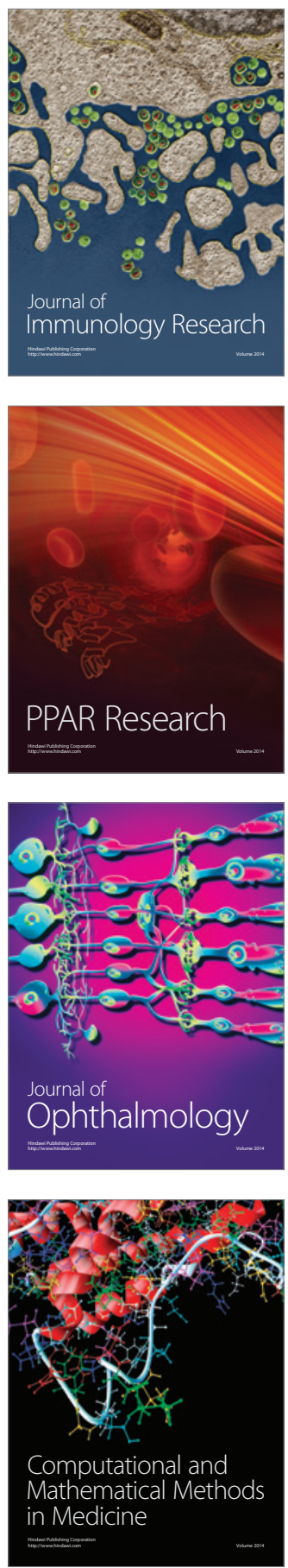

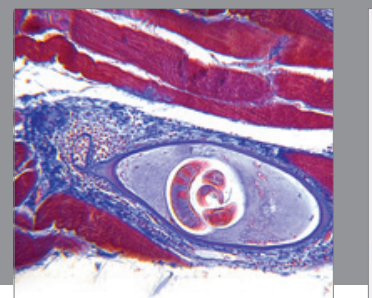

Gastroenterology

Research and Practice
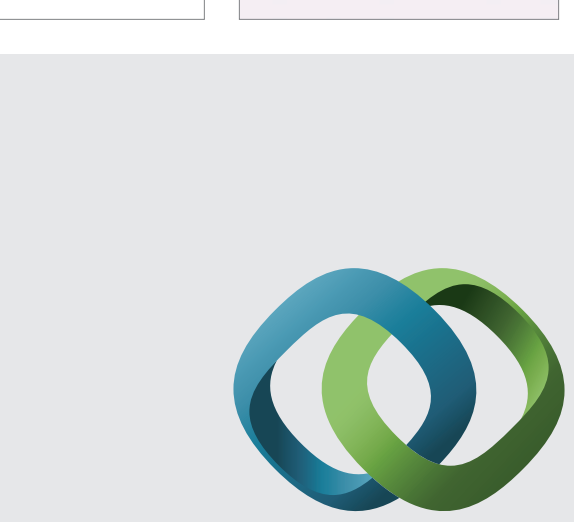

\section{Hindawi}

Submit your manuscripts at

http://www.hindawi.com
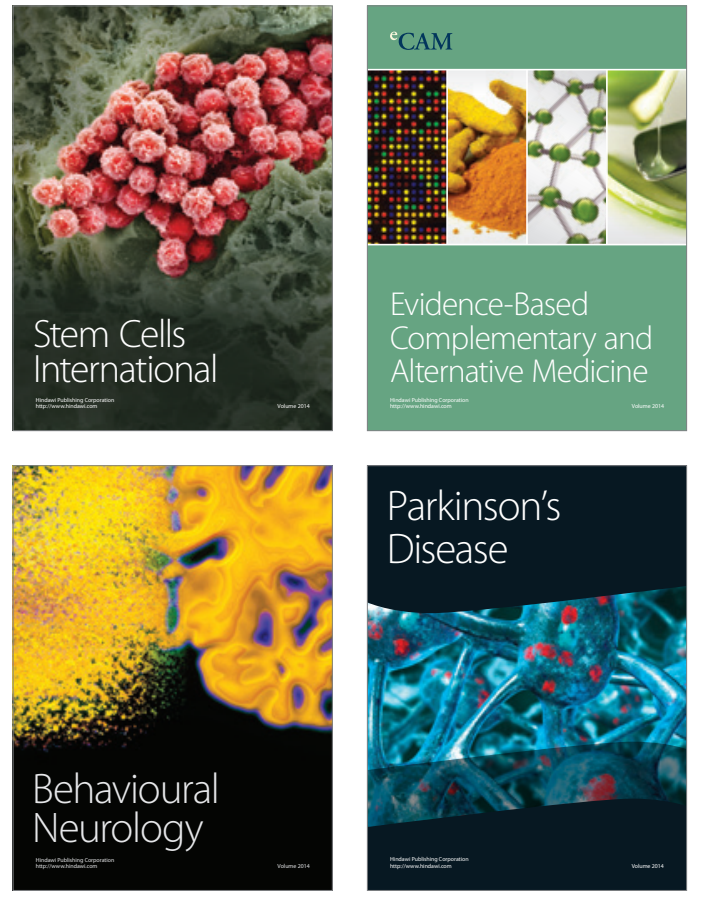
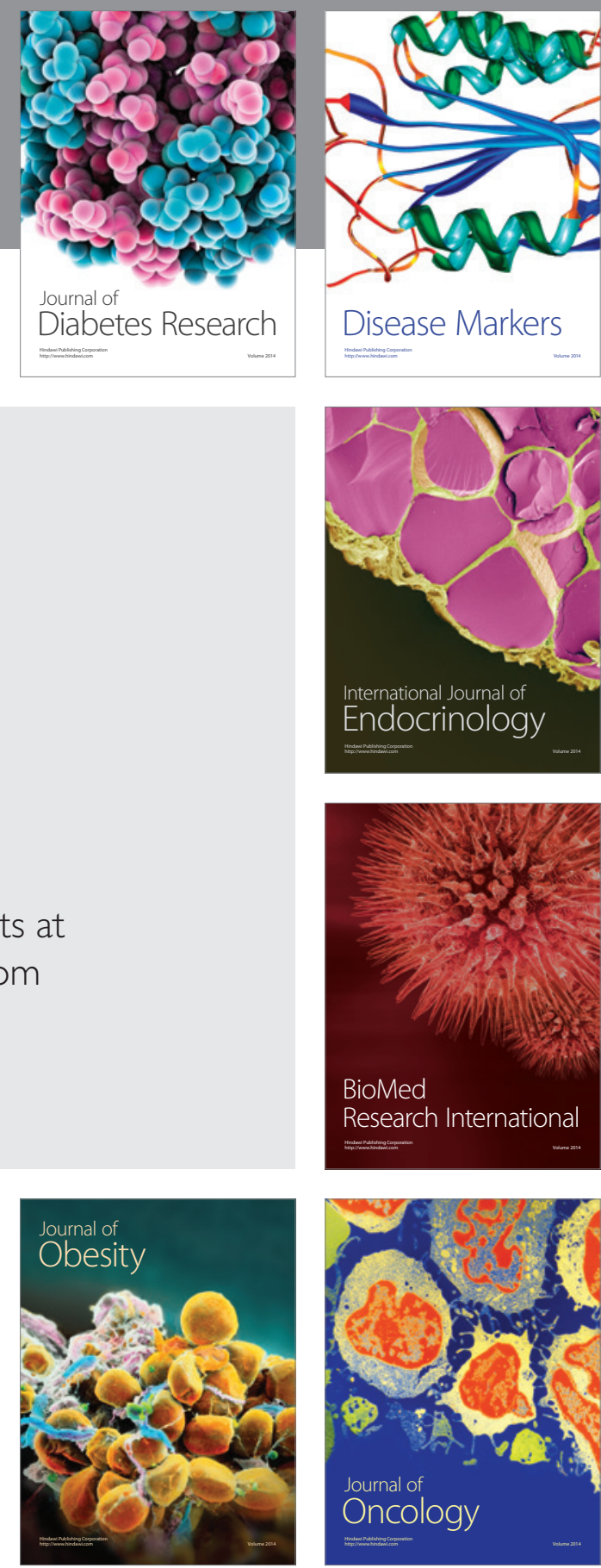

Disease Markers
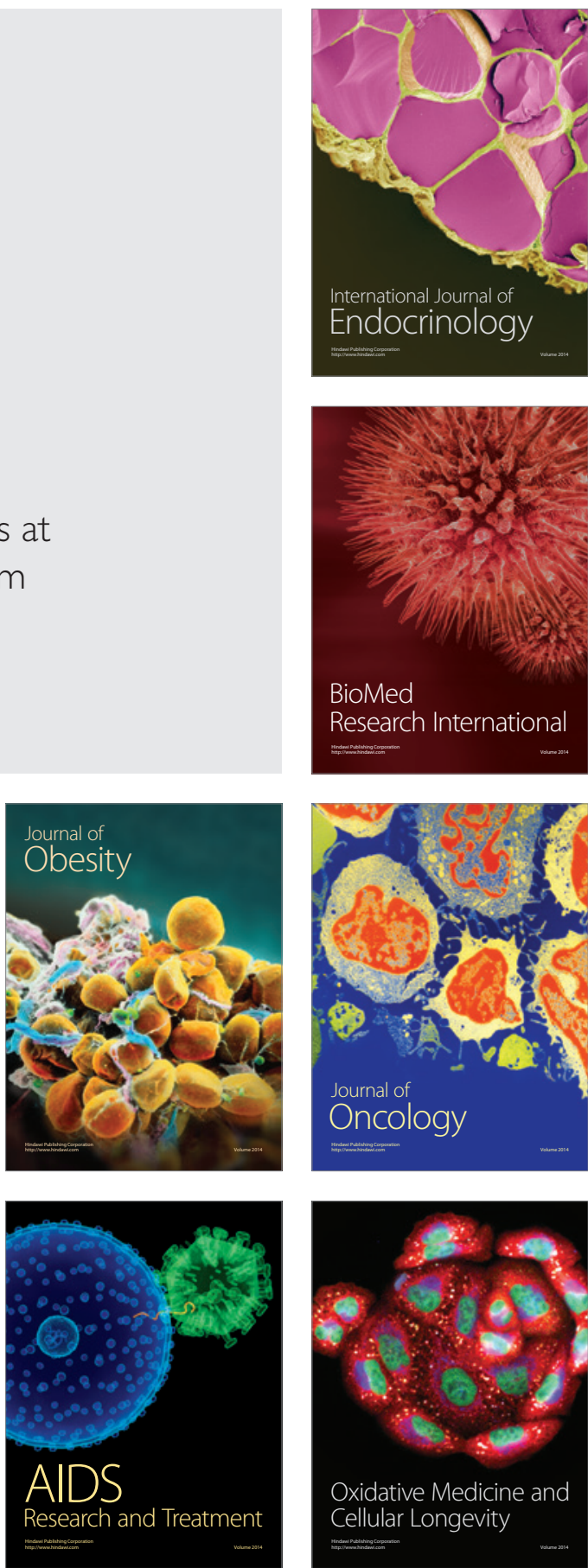